\title{
Litter Decomposability Traits and Their Linkage with the Cycling of Nutrients in the Forest Ecosystems under the Lens of Climate Change: A Conceptual Overview
}

\author{
Meenu Patil, Abhishek Kumar, Pardeep Kumar, A. N. Singh* \\ Department of Botany, Panjab University, India
}

Received December 31, 2019; Revised April 1, 2020; Accepted April 19, 2020

Copyright $\bigcirc 2020$ by authors, all rights reserved. Authors agree that this article remains permanently open access under the terms of the Creative Commons Attribution License 4.0 International License

\begin{abstract}
Litter decomposition is a key process that releases nutrients back to the ecosystem and therefore maintains the structure and functioning of the tropical forest ecosystems. The variations in the rate of litter decomposition among different ecosystems may be controlled by several factors including climate, litter quality and soil biota. However, the rapid change in the environmental conditions is expected to alter the rate of litter decomposition resulting in modified nutrient cycling. This modified cycling of the nutrient may disrupt the ecosystem structure and functions followed by the compromised quality of ecosystem services and functions. Thus, an improved understanding is needed about the factors affecting the decomposition rates to sustain biodiversity and ecosystem services in a changing environment. In this article, we tried to explain the various physical, chemical and biological factors that affect the litter decomposition and nutrient cycling in the forest ecosystem. To accomplish this, we synthesized the available information by carrying out a literature survey from available databases. We found that there is a shifting paradigm from climatic control to species traits control of litter decomposition rate and recently even moving beyond it considering the effects of soil biota and habitat effects too. Further, the rate of decomposition rate is linked with the cycling of nutrients and climatic effects are expected to cascade into ecosystem functions and their services. In order to get a clear picture, however, intensive studies are required to explore the coupling effects of climatic variation on the structure and functioning behaviour of the forest ecosystems to maintain biodiversity and their services in a changing environment.
\end{abstract}

Keywords Litter Decomposition, Forest Ecosystem, Litter Traits, Nutrient Cycling, Climate Change

\section{Introduction}

Every organism within an ecosystem requires energy and a set of specific essential nutrients for its perpetuation and function. These nutrients often enter the ecosystem from mineral rocks and fixation of atmospheric gases through physical, chemical and biological processes. Then, these nutrients are modified and transformed into organic matter by plants and other organisms after passing a very complicated process (energy transformation) or under process when they directly uptake or consume the energy by other organisms. This organic matter is once again made available to plants and organisms in the form of mineral nutrients through the attraction of microbes principally by the process of decomposition. In brief, this whole process of recycling and movement of nutrients across different components of the ecosystem is called nutrient cycling, which is an important attribute of all kinds of terrestrial ecosystems [1]. Since nutrient cycling is directly related to the growth of organisms in any ecosystem, it regulates the ecosystem structure and ecological services such as biomass production, carbon sequestration and other direct benefits to human society [2]. The structure of the plant community and plant growth consequently affected by the availability of nutrients by nutrient cycling and soil formation [2].

Hence, litter decomposition is an essential process that transforms the dead organic matter into mineral nutrients through the activity of microbial decomposers. The major source of organic matter in the soil is the plant litter and detritus of other organisms [1,2]. However, the rate of decomposition is not similar for all types of organic matter. Several factors influence the rate of litter decomposition including climate, litter quality (in terms of litter traits) and soil biota [2-4]. Understanding dominant factors of the litter decomposition rate are valuable as it is directly linked with nutrient cycling and ecosystem productivity. Further, 
the nutrient availability in the soil can substantially affect the species composition, ecosystem structure and ecological services.

Previous studies have shown that the rate of decomposition is influenced by the climatic conditions such as actual evapo-transpiration [3], mean annual temperature [5], mean annual precipitation [6] and solar radiation [7]; litter quality in terms of physico-chemical traits $[2,6,8,9]$; soil biota [10] and other factors such as the composition of litter [11] and methodological approaches [12]. Since these factors can be rapidly altered by the changing climate, we can expect substantial deviations in nutrient cycling and therefore the ecosystem services and functioning. However, these effects remained unclear due to the mixed results of the previous studies. Therefore, the present article aims to synthesize the possible effects of climate change on litter decomposability traits and nutrient cycling, particularly in the tropical forest ecosystems. To accomplish this, a literature search was carried out from the available electronic reference databases such as Google Scholar, Scopus and Web of Science. We have used the following keyword combinations for literature search: "Litter decomposition", "Litter AND Climate", "Litter AND Traits", "Litter AND factor", "Litter AND Litterbags" and "Litter AND Nutrient". We have included only those studies which have focused on the forest ecosystems. Additional information was collected from other sources such as books, theses, websites, monographs, and reports, etc. In this article, we have discussed how climate can influence the various factors on the litter decomposability traits and nutrient cycling. Thus, we tried to give answers to the following questions: 1) What are major factors that directly influence the litter decomposition in the tropical forest ecosystem? 2) How biotic factor(s) can affect litter decomposability traits? and 3) How nutrient cycling will respond to the changing climate in the tropical forest ecosystems?

\section{Factors Affecting Litter Decomposition}

Several factors affect the rate of litter decomposition that can be broadly classified as physical, chemical and biological factors depending on the nature of influencing factors. Alternatively, these factors can be divided into (i) litter quality, (ii) climatic conditions, (iii) soil biota and (iv) other factors like ecosystem and habitat type, physical geography, etc. Further, it has been observed that in general, litter traits alone explain a larger proportion of variations in litter decomposability followed by climatic factors followed by soil biota and other factors [2-4,9]. However, this general pattern may not be true for every kind of ecosystem due to the high variation in the environmental factors. The addition of nutrients in the soil may depend upon the litter quality, climate, individual nutrient concentration, and dynamics during the process of decomposition (Figure 1). Next, we discuss the various factors that affect the rate of decomposition and how climate can alter these factors to modify the decomposition rates.

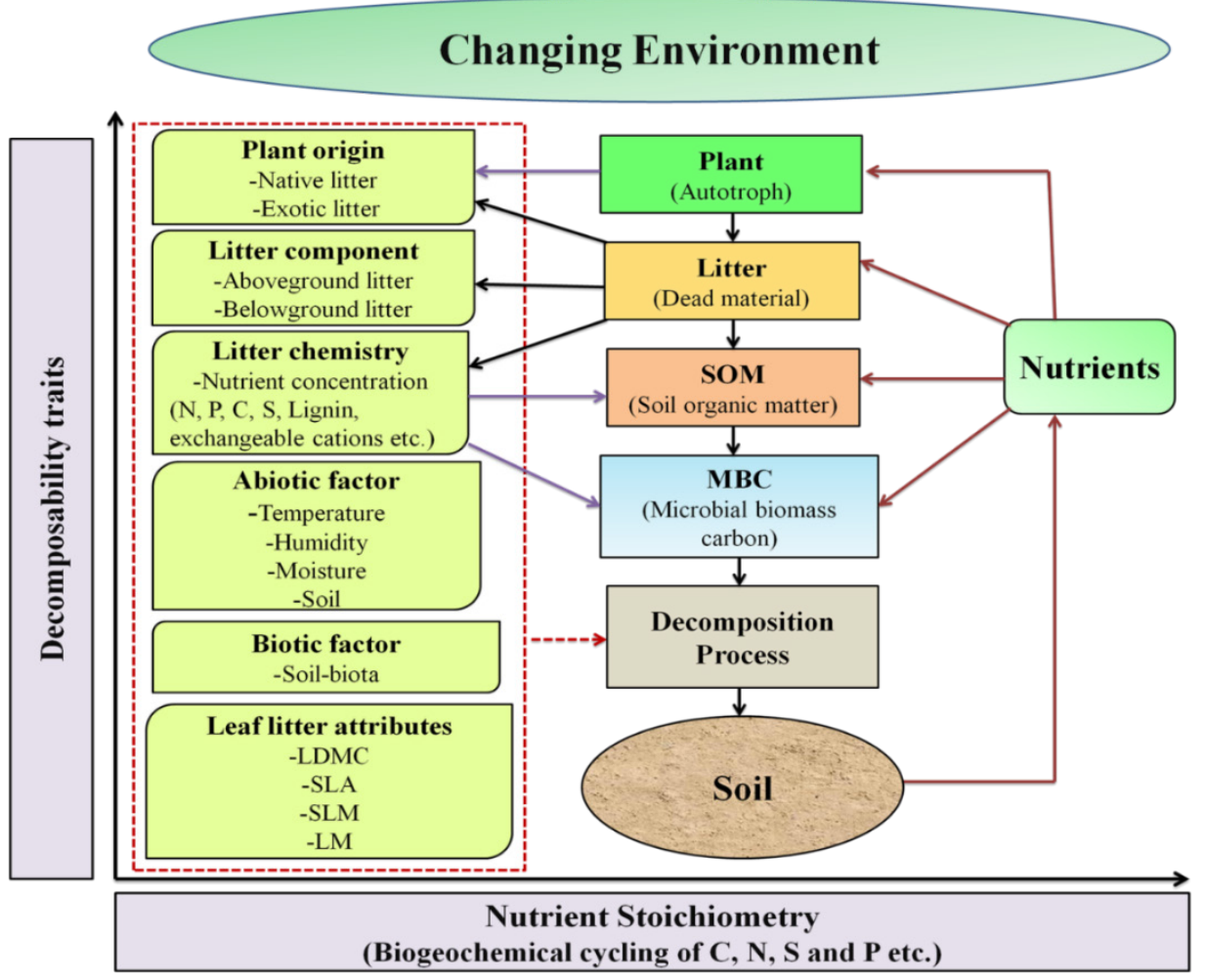


Figure 1. Conceptual model depicting various factors are affecting the litter decomposition process

\subsection{Litter Quality}

Litter input serves as the energy source for organisms residing in the soil component of the ecosystem. These decomposer organisms are detrital groups of the litter that converted it into inorganic form via mineralization during the decomposition process. Therefore, one can expect a higher rate of decomposition when a specific type of litter is preferred by the decomposers. Such a high-quality litter should have a high content of nutrients viz. $\mathrm{N}$ and $\mathrm{P}$ and high level of digestibility from the perspective of decomposer organisms [13]. Thus, the quality of litter in terms of physical and chemical traits can be responsible to promote the rate of decomposition.

\subsubsection{Physical Traits}

Among physical traits of the litter, specific leaf area (or specific leaf mass or leaf mass per area) $[14,15]$, litter dry matter content [16,17], litter $\mathrm{pH}[16]$, leaf tensile strength or toughness $[15,18,19]$ have been suggested to be important physical factors that may take part in the rate of decomposition. In conformity with this, collected studies indicated that litter with higher specific leaf area $[14,15]$ and lower dry matter content $[16,17]$ tend to be more easily degradable by decomposers and, therefore, results in a faster rate of decomposition $[13,20]$. Similarly, soft leaves tend to decompose faster as compared to tough leaves $[15,18,21]$. The slower rate of decomposition due to higher litter dry matter content can be attributed to increased rigidity which reduces palatability for decomposers [22]. Thus, leaf morphological traits are projected to shift due to changing environmental conditions $[23,24]$. Specific leaf area may likely increase with ongoing climate change, which may result in faster litter decomposition and therefore cycling of nutrients.

\subsubsection{Chemical Traits}

Litter chemistry is one of the most important factors that significantly influence the rate of litter decomposition. Chemical compounds that can be easily digested and yield more energy for decomposers are considered as high-quality litter. Therefore, litter chemical traits like carbon [2,25], lignin [26,27], nitrogen [28,29], phosphorus content [30], carbon to nitrogen ratio [9,28,31] and lignin to nitrogen ratio $[32,33]$ have been acknowledged as the dominant regulators of litter decomposition rates in the different ecosystems [8]. It has been further suggested that litter with high nutrients (carbon, nitrogen, phosphorus) and low amount of lignin tends to decompose faster because it will be easily degradable to decomposer groups and therefore said to be of 'high quality' $[13,20]$. Thus, in agreement with these reports, the chemical traits of the leaf litter have been considered as good promoters of the litter decomposition, and also, these might affect the activity of the soil decomposer group.

Since carbon is the main source of energy for the detrital group of the soil organisms, therefore, litter carbon content has been considered as an important driver of litter chemical quality $[2,25]$. More specifically, the chemical quality of litter depends on the types and nature of carbon-containing compounds and their bonds. For example, simple sugars like glucose are easily digestible and yield more energy, whereas, complex carbon-containing compounds like cellulose and lignin yield relatively lower energy when they are digested [34]. Thus, litter with a high amount of simpler sugar is considered to be of high quality whereas litter with a high amount of lignin is considered as of low quality. It has been already shown that litter rich in available $\mathrm{C}$ compounds (non-structural carbohydrates, phenolics) tends to decompose faster as compared to litter rich in recalcitrant $C$ (condensed tannins and lignin) in tropical forests [25]. Further, secondary metabolites such as condensed tannins or the polyphenols tend to inhibit the decomposition because they form a recalcitrant complex with proteins that are not easily degradable by the decomposer organisms. [35,36]. Thus, the accumulation of recalcitrant polyphenolic compounds slows down the decomposition rate during the later stages.

Lignin is a polysaccharide compound produced by plants for defence purposes and it yields a very low amount of energy to the decomposers. Due to the poor quality as an energy source, litter lignin content has been widely used as an index of litter quality [26-28]. In general, the litter lignin tends to retard the rate of decomposition across different ecosystems and therefore, has great effects on nutrient cycling [8,9]. The slower rate of decomposition due to higher lignin content can be attributed to increased rigidity which reduces palatability to decomposers. Thus, the degradation rate of lignin is substantially affected by the composition of the decomposer organism because lignin is chiefly degraded by fungal members of the basidiomycetes. Furthermore, lignin control of decay rates may be species-specific due to variability in lignin content in the litter of different species found in the tropical ecosystems [37]. Thus, litter quality cannot be solely attributed to the lignin content of litter and other chemical factors such as nitrogen and phosphorus may exert a strong influence on litter decay rates.

Nitrogen is an important nutrient, which is required for the growth and metabolism of decomposer organisms. Thus, the litter nitrogen content is another important chemical trait of the litter that affects the rate of decomposition substantially [8,9]. The activity and metabolism of decomposer organisms are affected by the supply of nitrogen because it is often limited in the forest ecosystems [37]. This is why higher nitrogen content in litter tends to promote a higher rate of litter decomposition as evidenced by the positive relation between litter nitrogen content and decomposition rate found in the 
previous studies [28,29,32,33]. This faster decomposition with higher litter nitrogen can be attributed to increased activity of associated microbial communities and soil-decomposer fauna [38].

Similar to nitrogen, phosphorus content is also an essential requirement by the plants as well as by the decomposers for their growth and development; therefore, considered an important litter chemical trait that influences the rate of litter decomposition in the forest ecosystems [9]. The higher phosphorus content in the litter results in a faster decomposition rate as evidenced by a positive correlation between the phosphorus content and decomposition rate [30,39-41]. This may be due to increased phosphorus availability to soil biota which may increase their litter breakdown activity. In addition to these chemical traits, some other macro- and micronutrient elements such as calcium, magnesium, potassium and sulphur also affect the rate of decomposition [9]. Thus, in general, higher nutrient content of litter tends to increase the rate of litter decomposition primarily due to increased activity of decomposer micro-organisms.

Since some low energy sources such as cellulose and lignin tend to slow down decomposition rate whereas some high nutrient compounds like nitrogen and phosphorus tend to increase the decomposition rate, therefore, a ratio of the same can be a key predictor of litter quality due to their complementary effects. This is why, carbon to nitrogen ratio $[9,28,31]$ and lignin to nitrogen ratio $[32,33]$ are reported as good predictors of the litter decomposition rate; however, as compared to $\mathrm{C}$ : $\mathrm{N}$ ratio, lignin to nitrogen ratio is more pronounced that significantly correlated with litter decomposition [9]. Thus, nutrient cycling, especially carbon and nitrogen dynamics are greatly influenced by the chemistry of leaf litter.

\subsubsection{Species Identity}

Species identity is an important factor that controls the rate of decomposition through the effects of litter quality [42]. In particular, the origin of species (i.e. native or exotic) may have effects on the litter decomposition rates due to differences in their litter qualities. It has been further suggested that invasive species usually have higher litter quality and therefore exhibit faster decomposition rates and nutrient cycling [33,38]; though it is not always true $[31,43]$. The enhanced decomposition in the case of invasive exotic plants can be attributed to their higher leaf litter quality in terms of higher leaf nitrogen content, which is preferred by the decomposers [43]. Similarly, species composition can also have differential effects on the decomposition rates due to similar reasons.

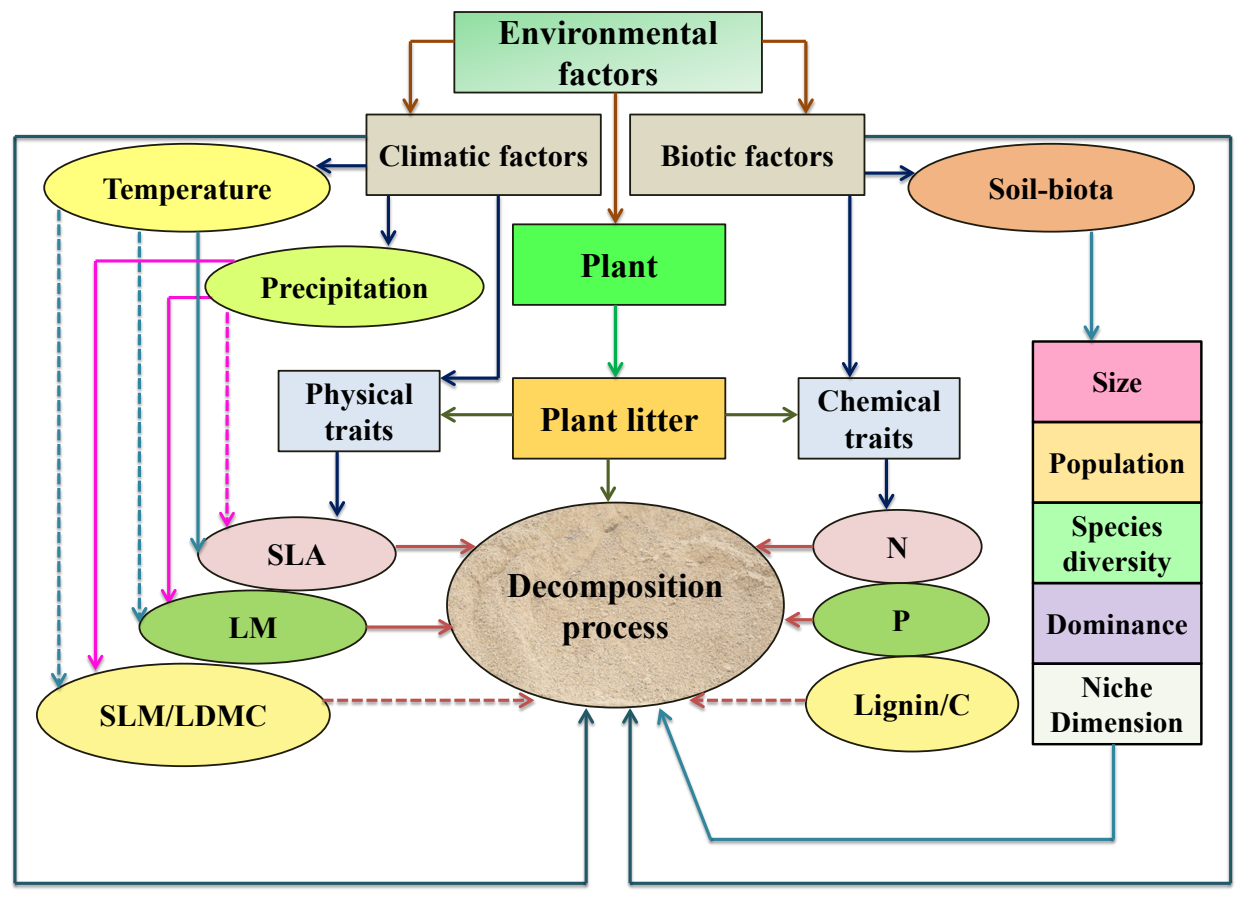

Figure 2. Diagrammatic representation of the effect of environmental factors on the litter decomposition process. Solid arrows indicate positive effects whereas dashed lines indicate negative effects. SLA = specific leaf area, LM = leaf moisture, SLM $=$ Specific leaf mass, LDMC $=$ Litter dry matter content, $\mathrm{N}=$ litter nitrogen, $\mathrm{P}=$ litter phosphorus, $\mathrm{C}=$ litter carbon content 


\subsection{Environmental Factors}

Apart from litter quality, climatic conditions directly affect the rate of litter decomposition by influencing the activity of decomposer organisms [3]. Among climatic conditions, temperature and precipitation are perhaps the most important factors that affect the activity and metabolism of decomposer organisms. In general, high temperature and moist conditions are optimum for the activity of decomposers, therefore, decomposition rate is usually higher in warmer and moist environments such as tropical forests. Further, seasonal drying and wetting/rewetting tends to reduce the activity and abundance of the soil organisms. Due to strong climatic controls of litter decomposition rates, changing climate is now expected to alter decomposition rates, nutrient cycling and finally, the productivity of the plants (Figure 2).

Temperature is an important factor that directly influences the activity of the decomposer organisms and simultaneously the rate of litter decomposition [42]. Therefore, higher temperature promotes faster decomposition of litter and a positive correlation between their rates with mean annual temperature is observed in several reports [9,44-46]. However, this temperature sensitivity might be influenced by litter quality [47].

Similarly, precipitation also affects the rate of decomposition by influencing the litter quality and soil moisture [9]. Higher precipitation is associated with an increased decomposition rate and a positive correlation is observed between the litter decomposition rate and mean annual precipitation [9]. Thus, a decrease in rainfall patterns may suppress decomposition rates [46,48]. This is because higher precipitation tends to increase the litter moisture content, which resulted in rapid decomposition by increased leaching [49].

Evapo-transpiration has been used as an index for the effects of climate on litter decomposition rate because it combines the effects of temperature and precipitation. Since temperature and precipitation are significantly responsible that directly affects the activity of decomposer organisms, therefore, evapo-transpiration must be correlated to the rate of litter decomposition. It has been acknowledged that higher actual evapo-transpiration (AET) results in faster decomposition of the litter as indicated by a positive correlation between decomposition rate and AET $[3,26]$. Thus, a higher rate of litter decomposition in tropical forests can be attributed to their high AET rates.

Apart from the above major climatic factors, solar radiation is considered an important driver of decomposition in some harsh environments such as deserts and arid ecosystems [50]. In such ecosystems, the intensity of solar radiation including UV-B radiations augmenting as a factor that substantially affects the decomposition rates [51,52]. It has been observed that such photodegradation tends to enhance decomposition in deserts and semi-arid ecosystems [50-52] whereas it has minor effects in tropical wetter ecosystems [7].

Since litter deposition in the terrestrial ecosystems usually occurs on the soil surface and the decomposers generally reside in the soil, therefore, interactions with soil factors, soil biota and litter establish a triangular relationship. In this relationship, soil factors impart importance to control for the litter decomposition rates. For example, the soil temperature is an important controller of the population size of soil biota that is actively involved in the decomposition process and may significantly affect their rates [53]. Further, soil moisture is another important parameter because microbial activities depend on moisture levels. Optimum moisture conditions tend to enhance the litter decomposition process, whereas, waterlogged conditions may retard their rates due to limited oxygen supply to the decomposer organisms [54]. Similarly, soil nutrients also affect the activity of microbial organisms, therefore, fertile soils with high nutrient contents tend to increase decomposer activity and enhance the rate of decomposition [55-57]. Although the addition of nutrients to the soil increased the litter quality overall decomposition rate slowed done [58]. It might be possible because decomposer organisms utilized more energy and nutrients from directly supplied nutrients than breaking down the litter.

\subsection{Biotic Factors}

Decomposition is a complex process that involves fragmentation and chemical processing of litter by ingestion and egestion of organic matter. Both these processes are accomplished by organisms of varying sizes and functions. Although all heterotrophs carry out some sort of chemical modification of organic matter by ingestion, digestion and egestion, however some specialized organisms that feed on the litter and detritus are called detritivores or decomposer communities. These decomposer organisms can be classified based on their size and function [1].

Fragmentation is an important process that aids decomposition chiefly carried out by large-sized animals such as earthworms and snails. The role of different soil organisms has been disentangled by studying the effect of varying mesh-sized bags on the rate of decomposition. It has been shown that a litter bag with larger mesh size tends to exhibit rapid decomposition rate due to higher fragmentation carried out by large-sized decomposer animals [59].

Chemical processing of litter involves enzymatic degradation of organic matter into inorganic mineral nutrients. This chemical modification is chiefly carried out by micro-organisms such as bacteria and fungi. Off which, bacteria feed dominantly on animal detritus whereas fungi are usually associated with decomposition of dead organic matter derived from plants. It has been speculated that the 
decomposer group may become specialized to decompose a particular type of litter of a species [10] and therefore, expected to increase the decomposition rate of the litter received from the plants just above them. A considerable amount of evidence acknowledges that the litter of a species decomposes rapidly on a site where it has to be naturally fallen and decomposed as compared to other sites $[56,60]$. This effect is usually referred to as the "home-field advantage (HFA)" [61], though it is not necessarily observed in all cases, especially where litters of similar quality were incubated in the ecosystems with multiple dominant species [62-64]. Thus, these inconsistencies indicate that the specialization of the decomposer group is not the only mechanism that leads to the HFA effect.

Apart from the direct effects of decomposer organisms, decomposition rates can also be indirectly affected by the presence of other species such as herbivores and invaders via species-species interactions. For example, the presence of a high degree of herbivores may induce plants to develop structural compounds as defence chemicals, thus altering the litter chemistry which ultimately affects the decomposition rates [65]. Similarly, invaders may also force chemical alterations of the litter quality leading to modified decomposition rates [66]. Thus, living organisms can also substantially affect the decomposition process via direct and indirect pathways. Direct pathways include the decomposer organisms whereas indirect pathways include species interactions that induce changes in the litter quality and environmental conditions.

\subsection{Other factors}

Geographic factors such as latitude and elevation can affect the rates of litter decomposition through the effects of climatic, environmental and species compositions. It has been observed that the overall decomposition process tends to decrease as one moves from lower to higher latitudes $[9,67]$. A similar pattern was also observed along the elevation [53]. Both these variations indicate the climatic control of decomposition rates on global scales. Among forest types, rainforests exhibit higher decomposition rates as compared to other forest types such as coniferous forests [9]. Similarly, green leaves decomposed rapidly as compared to woods among plant parts [9].

\section{Nutrient Cycling and Climate Change}

Nutrient cycling is directly related to the rate of decomposition, thus higher decomposition rates will lead to faster nutrient cycling leading to higher productivity. Strong climatic controls of litter decomposition rate over a global scale indicate its sensitivity to ongoing rates of climate change [58]. Since future climatic conditions are predicted to have increased temperature and frequent droughts due to irregular precipitation patterns [68], several direct and indirect effects of changing climate can disrupt this natural flow of nutrients in different components of the ecosystems [69].

In order to adapt to changing climatic conditions, plants may reprogram or re-organize their morphological and physiological features leading to altered litter quality [6972]. These altered morpho-physiological traits will eventually affect the litter quality and therefore the decomposition process [8]. Further, climate warming is expected to increase the rate of decomposition more in tropical forests due to the increased activity of decomposer organisms $[44,53]$. Also, altered temperature and precipitation regimes affect the microbial composition in soils, which will again contribute to altered nutrient cycling [73]. Similarly, atmospheric $\mathrm{CO}_{2}$ concentration is also expected to affect the rate of litter decomposition $[70,71]$. Since $\mathrm{CO}_{2}$ fixation by the plants is directly related to their litter quality, alterations in the $\mathrm{CO}_{2}$ will exert its effects on decomposition rates [72]. It has been observed that elevated $\mathrm{CO}_{2}$ concentrations tend to decrease the rate of decomposition via increasing the litter lignin to nitrogen ratio, although these effects were smaller [72].

\section{Conclusions}

Litter decomposition is a very complex process that controls global nutrient cycling, productivity and ecosystem functioning and their services. Several factors including litter quality, climatic and biotic factors influence interactively the rate of decomposition in the terrestrial ecosystems. A high-quality litter composed of easily degradable energy sources and high nutrients tends to decompose faster. Among litter quality, litter lignin to nitrogen or carbon to nitrogen ratio is an important controller of decay rates. Among climatic factors, mean annual temperature and precipitation-derived soil moisture are important influencing factors. All these factors affect litter decomposition rate via influencing activity, growth and metabolism of the decomposer organisms. Our knowledge about the factors controlling nutrient cycling has advanced from climatic controls to litter quality controls of litter decomposition rates and both factors together explain more than $80 \%$ of the total variation in litter decomposability across different ecosystem types. Overall, the effects of changing climate seem to reduce the litter decomposition rate, resulting in slow nutrient cycling, which in turn compromises the ecosystem services and functions through reduced productivity. However, still limited information is available about the climatic effects on litter decomposition and nutrient cycling across global forest ecosystems particularly of tropical forests where climate change has been included as a regulatory factor in the decomposition mechanism. Therefore, an improved understanding of decomposability 
traits and cycling of nutrients urgently required to sustain biodiversity function and services of the forest ecosystems under the lens of climate change.

\section{Acknowledgements}

The authors are grateful to the Chairperson, Department of Botany, Panjab University, Chandigarh, for providing all the necessary facilities required for the work. The first three authors were supported by the University Grants Commission (UGC), Government of India, New Delhi in the form of Junior Research Fellowship [UGC Ref. No.: 507-(OBC) (CSIR-UGC NET DEC. 2016)]. The corresponding author acknowledges the Department of Science and Technology, Government of India, for support in the form of PURSE Grant.

\section{REFERENCES}

[1] W. D. Bowman, S. D. Hacker, M. L. Cain. Ecology, 4th ed. Sinauer Associates, Inc. Publishers, Sunderland, Massachusetts, U.S.A., 2017.

[2] S. Hättenschwiler, S. Coq, S. Barantal, I. T. Handa. Leaf traits and decomposition in tropical rainforests: revisiting some commonly held views and towards a new hypothesis, New Phytologist, Vol.189, No.4, 950-965, 2011.

[3] R. Aerts. Climate, Leaf Litter Chemistry and Leaf Litter Decomposition in Terrestrial Ecosystems: A Triangular Relationship, Oikos, Vol.79, No.3, 439-449, 1997.

[4] M. M. Cou teaux, P. Bottner, B. Berg. Litter decomposition, climate and litter quality, Trends in Ecology \& Evolution, Vol.10, No.2, 63-66, 1995.

[5] B. Berg. Decomposition patterns for foliar litter - A theory for influencing factors, Soil Biology and Biochemistry, Vol.78, 222-232, 2014.

[6] C. E. Prescott. Litter decomposition: What controls it and how can we alter it to sequester more carbon in forest soils?, Biogeochemistry, Vol.101, No.1, 133-149, 2010.

[7] O. A. Marinho, L. A. Martinelli, P. J. Duarte-Neto, E. A. Mazzi, J. Y. King. Photodegradation influences litter decomposition rate in a humid tropical ecosystem, Brazil, Science of the Total Environment, Vol.715, 136601, 2020.

[8] W. K. Cornwell, J. H. C. Cornelissen, K. Amatangelo, E. Dorrepaal, V. T. Eviner, O. Godoy, S. E. Hobbie, B. Hoorens, H. Kurokawa, N. Pérez-Harguindeguy, H. M. Quested, L. S. Santiago, D. A. Wardle, I. J. Wright, R. Aerts, S. D. Allison, P. Van Bodegom, V. Brovkin, A. Chatain, T. V. Callaghan, S. Díaz, E. Garnier, D. E. Gurvich, E. Kazakou, J. A. Klein, J. Read, P. B. Reich, N. A. Soudzilovskaia, M. V. Vaieretti, M. Westoby. Plant species traits are the predominant control on litter decomposition rates within biomes worldwide, Ecology Letters, Vol.11, No.10, 1065-1071, 2008.

[9] D. Zhang, D. Hui, Y. Luo, G. Zhou. Rates of litter decomposition in terrestrial ecosystems: global patterns and controlling factors, Journal of Plant Ecology, Vol.1, No.2, 85-93, 2008.

[10] E. Ayres, H. Steltzer, S. Berg, D. H. Wall. Soil biota accelerate decomposition in high-elevation forests by specializing in the breakdown of litter produced by the plant species above them, Journal of Ecology, Vol.97, No.5, 901912, 2009.

[11] S. Hättenschwiler, A. V Tiunov, S. Scheu. Biodiversity and Litter Decomposition in Terrestrial Ecosystems, Annual Review of Ecology, Evolution, and Systematics, Vol.36, No.1, 191-218, 2005.

[12] S. Bokhorst, D. A. Wardle. Microclimate within litter bags of different mesh size: Implications for the "arthropod effect" on litter decomposition, Soil Biology and Biochemistry, Vol.58, 147-152, 2013.

[13] J. H. C. Cornelissen, H. M. Quested, D. Gwynn-Jones, R. S. P. Van Logtestijn, M. A. H. De Beus, A. Kondratchuk, T. V. Callaghan, R. Aerts. Leaf digestibility and litter decomposability are related in a wide range of subarctic plant species and types, Functional Ecology, Vol.18, No.6, 779-786, 2004.

[14] G. Liu, L. Wang, L. Jiang, X. Pan, Z. Huang, M. Dong, J. H. C. Cornelissen. Specific leaf area predicts dryland litter decomposition via two mechanisms, Journal of Ecology, Vol.106, No.1, 218-229, 2018.

[15] J. H. C. Cornelissen, N. Pérez-Harguindeguy, S. Díaz, J. P. Grime, B. Marzano, M. Cabido, F. Vendramini, B. Cerabolini. Leaf structure and defence control litter decomposition rate across species and life forms in regional floras on two continents, New Phytologist, Vol.143, No.1, 191-200, 1999.

[16] J. Tao, J. Zuo, Z. He, Y. Wang, J. Liu, W. Liu, J. H. C. Cornelissen. Traits including leaf dry matter content and leaf $\mathrm{pH}$ dominate over forest soil $\mathrm{pH}$ as drivers of litter decomposition among 60 species, Functional Ecology, Vol.33, No.9, 1798-1810, 2019.

[17] R. J. Pakeman, A. Eastwood, A. Scobie. Leaf dry matter content as a predictor of grassland litter decomposition: A test of the "mass ratio hypothesis," Plant and Soil, Vol.342, No.1-2, 49-57, 2011.

[18] N. Pérez-Harguindeguy, S. Díaz, J. H. C. Cornelissen, F. Vendramini, M. Cabido, A. Castellanos. Chemistry and toughness predict leaf litter decomposition rates over a wide spectrum of functional types and taxa in central Argentina, Plant and Soil, Vol.218, No.1-2, 21-30, 2000.

[19] A. Gallardo, J. Merino. Leaf decomposition in two Mediterranean ecosystems of southwest Spain: influence of substrate quality, Ecology, Vol.74, No.1, 152-161, 1993.

[20] I. Bumb, E. Garnier, S. Coq, J. Nahmani, M. Del Rey Granado, O. Gimenez, E. Kazakou. Traits determining the digestibility-decomposability relationships in species from Mediterranean rangelands, Annals of Botany, Vol.121, No.3, 459-469, 2018.

[21] J. H. C. Cornelissen, K. Thompson. Functional leaf attributes predict litter decomposition rate in herbaceous plants, New Phytologist, Vol.135, No.1, 109-114, 1997.

[22] M. Ardón, C. M. Pringle. Do secondary compounds inhibit 
microbial- and insect-mediated leaf breakdown in a tropical rainforest stream, Costa Rica?, Oecologia, Vol.155, No.2, 311-323, 2008.

[23] J. Stropp, M. Isiane, S. Ricardo. Drier climate shifts leaf morphology in Amazonian trees, Oecologia, Vol.185, No.3, 525-531, 2017.

[24] P. Agnihotri, T. Husain, P. A. Shirke, O. P. Sidhu, H. Singh, V. Dixit, A. A. Khuroo, D. V. Amla, C. S. Nautiyal. Climate change-driven shifts in elevation and ecophysiological traits of Himalayan plants during the past century, Current Science, Vol.112, No.3, 595-601, 2017.

[25] S. Hättenschwiler, H. B. Jørgensen. Carbon quality rather than stoichiometry controls litter decomposition in a tropical rain forest, Journal of Ecology, Vol.98, No.4, 754-763, 2010.

[26] V. Meentemeyer. Macroclimate and lignin control of litter decomposition rates, Ecology, Vol.59, No.3, 465-472, 1978.

[27] A. Frainer, M. S. Moretti, W. Xu, M. O. Gessner. No evidence for leaf-trait dissimilarity effects on litter decomposition, fungal decomposers, and nutrient dynamics, Ecology, Vol.96, No.2, 550-561, 2015.

[28] B. R. Taylor, D. Parkinson, W. F. J. Parsons. Nitrogen and Lignin Content as Predictors of Litter Decay Rates: A Microcosm Test, Ecology, Vol.70, No.1, 97-104, 1989.

[29] E. Hernández, E. J. Questad, W. M. Meyer, K. N. Suding. The effects of nitrogen deposition and invasion on litter fuel quality and decomposition in a Stipa pulchra grassland, Journal of Arid Environments, Vol.162, 35-44, 2019.

[30] D. S. Schimel, B. H. Braswell, E. A. Holland, R. McKeown, D. S. Ojima, T. H. Painter, W. J. Parton, A. R. Townsend. Climatic, edaphic, and biotic controls over storage and turnover of carbon in soils, Global Biogeochemical Cycles, Vol.8, No.3, 279-293, 1994.

[31] M. Bottollier-Curtet, J. Y. Charcosset, A. M. Planty-Tabacchi, E. Tabacchi. Chemical composition rather than plant geographic origin drives the breakdown of riparian plant litter with changes in associated invertebrate diversity, Plant and Soil, Vol.390, No.1-2, 265-278, 2015.

[32] J. M. Melillo, J. D. Aber, J. F. Muratore. Nitrogen and lignin control of hardwood leaf litter decomposition dynamics, Ecology, Vol.63, No.3, 621-626, 1982.

[33] G. Incerti, F. Cartenì, G. Cesarano, T. C. Sarker, A. M. Abd El-Gawad, R. D'Ascoli, G. Bonanomi, F. Giannino. Faster N release, but not $\mathrm{C}$ loss, from leaf litter of invasives compared to native species in mediterranean ecosystems, Frontiers in Plant Science, Vol.9, 534, 2018.

[34] M. J. Swift, O. W. Heal, J. M. Anderson. Decomposition in Terrestrial Ecosystems. University of California Press, Berkeley, 1979.

[35] C. Ristok, K. N. Leppert, K. Franke, M. Scherer-Lorenzen, P. A. Niklaus, L. A. Wessjohann, H. Bruelheide. Leaf litter diversity positively affects the decomposition of plant polyphenols, Plant and Soil, Vol.419, No.1-2, 305-317, 2017.

[36] P. García-Palacios, E. A. Shaw, D. H. Wall, S. Hättenschwiler. Temporal dynamics of biotic and abiotic drivers of litter decomposition, Ecology Letters, Vol.19,
No.5, 554-563, 2016.

[37] J. M. Bhatnagar, K. G. Peay, K. K. Treseder. Litter chemistry influences decomposition through activity of specific microbial functional guilds, Ecological Monographs, Vol.88, No.3, 429-444, 2018.

[38] R. Aragón, L. Montti, M. M. Ayup, R. Fernández. Exotic species as modifiers of ecosystem processes: Litter decomposition in native and invaded secondary forests of NW Argentina, Acta Oecologica, Vol.54, 21-28, 2014.

[39] M. Hirobe, J. Sabang, B. K. Bhatta, H. Takeda. Leaf-litter decomposition of 15 tree species in a lowland tropical rain forest in Sarawak: Decomposition rates and initial litter chemistry, Journal of Forest Research, Vol.9, No.4, 341-346, 2004.

[40] Y. Peng, W. Yang, K. Yue, B. Tan, C. Huang, Z. Xu, X. Ni, L. Zhang, F. Wu. Temporal dynamics of phosphorus during aquatic and terrestrial litter decomposition in an alpine forest, Science of The Total Environment, Vol.642, 832-841, 2018.

[41] G. F. C. Veen, M. K. Sundqvist, D. A. Wardle. Environmental factors and traits that drive plant litter decomposition do not determine home-field advantage effects, Functional Ecology, Vol.29, No.7, 981-991, 2015.

[42] J. Esquivel, B. B. Park, F. Casanoves, D. Delgado, G. E. Park, B. Finegan. Altitude and species identity drive leaf litter decomposition rates of ten species on a $2950 \mathrm{~m}$ altitudinal gradient in Neotropical rain forests, Biotropica, Vol.52, No.1, 11-21, 2020.

[43] I. Jo, J. D. Fridley, D. A. Frank. More of the same? In situ leaf and root decomposition rates do not vary between 80 native and nonnative deciduous forest species, New Phytologist, Vol.209, No.1, 115-122, 2016.

[44] L. D. Bothwell, P. C. Selmants, C. P. Giardina, C. M. Litton. Leaf litter decomposition rates increase with rising mean annual temperature in Hawaiian tropical montane wet forests, PeerJ, Vol.2014, No.2, 2014.

[45] X. He, Y. Lin, G. Han, P. Guo, X. Tian. The effect of temperature on decomposition of leaf litter from two tropical forests by a microcosm experiment, European Journal of Soil Biology, Vol.46, No.3-4, 200-207, 2010.

[46] T. R. Moore, J. A. Trofymow, B. Taylor, C. Prescott, C. Camiré, L. Duschene, J. Fyles, L. Kozak, M. Kranabetter, I. Morrison, M. Siltanen, S. Smith, B. Titus, S. Visser, R. Wein, S. Zoltai. Litter decomposition rates in Canadian forests, Global Change Biology, Vol.5, No.1, 75-82, 1999.

[47] N. Fierer, J. M. Craine, K. Mclauchlan, J. P. Schimel. Litter quality and the temperature sensitivity of decomposition, Ecology, Vol.86, No.2, 320-326, 2005.

[48] S. Zhou, C. Huang, Y. Xiang, L. Tie, B. Han, S. Scheu. Effects of reduced precipitation on litter decomposition in an evergreen broad-leaved forest in western China, Forest Ecology and Management, Vol.430, 219-227, 2018.

[49] T. Kutlu, A. K. Guber, M. L. Rivers, A. N. Kravchenko. Moisture absorption by plant residue in soil, Geoderma, Vol.316, 47-55, 2018.

[50] A. T. Austin, L. Vivanco. Plant litter decomposition in a semi-arid ecosystem controlled by photodegradation, Nature, Vol.442, No.7102, 555-558, 2006. 
[51] V. A. Pancotto, O. E. Sala, T. M. Robson, M. M. Caldwell, A. L. Scopel. Direct and indirect effects of solar ultraviolet-B radiation on long-term decomposition, Global Change Biology, Vol.11, No.11, 1982-1989, 2005.

[52] A. Gaxiola, J. J. Armesto. Understanding litter decomposition in semiarid ecosystems: Linking leaf traits, UV exposure and rainfall variability, Frontiers in Plant Science, Vol.6, 140, 2015.

[53] N. Salinas, Y. Malhi, P. Meir, M. Silman, R. Roman Cuesta, J. Huaman, D. Salinas, V. Huaman, A. Gibaja, M. Mamani, F. Farfan. The sensitivity of tropical leaf litter decomposition to temperature: Results from a large-scale leaf translocation experiment along an elevation gradient in Peruvian forests, New Phytologist, Vol.189, No.4, 967-977, 2011.

[54] K. Peña-Peña, U. Irmler. Moisture seasonality, soil fauna, litter quality and land use as drivers of decomposition in Cerrado soils in SE-Mato Grosso, Brazil, Applied Soil Ecology, Vol.107, 124-133, 2016.

[55] P. H. Nye. Organic matter and nutrient cycles under moist tropical forest, Plant and Soil, Vol.13, No.4, 333-346, 1960.

[56] Z. Yu, Z. Huang, M. Wang, R. Liu, L. Zheng, X. Wan, Z. Hu, M. R. Davis, T. C. Lin. Nitrogen addition enhances home-field advantage during litter decomposition in subtropical forest plantations, Soil Biology and Biochemistry, Vol.90, 188-196, 2015.

[57] M. Knorr, S. D. Frey, P. S. Curtis. Nitrogen additions and litter decomposition: A meta-analysis, Ecology, Vol.86, No.12, 3252-3257, 2005.

[58] L. Huttunen, P. J. Aphalo, T. Lehto, P. Niemelä, K. Kuokkanen, S. Kellomäki. Effects of elevated temperature, elevated $\mathrm{CO}_{2}$ and fertilization on quality and subsequent decomposition of silver birch leaf litter, Soil Biology and Biochemistry, Vol.41, No.12, 2414-2421, 2009.

[59] C. A. Edwards, G. W. Heath. The role of soil animals in breakdown of leaf material, In Soil Organisms, J. Doeksen and J. Van der Drift, Eds. North Holland Publishing Co, Amsterdam, Netherlands, 1963, 76-84.

[60] Y. Li, N. Chen, M. E. Harmon, Y. Li, X. Cao, M. A. Chappell, J. Mao. Plant species rather than climate greatly alters the temporal pattern of litter chemical composition during long-term decomposition, Scientific Reports, Vol.5, 15783, 2015.

[61] H. L. Gholz, D. A. Wedin, S. M. Smitherman, M. E. Harmon, W. J. Parton. Long-term dynamics of pine and hardwood litter in contrasting environments: Toward a global model of decomposition, Global Change Biology, Vol.6, No.7, 751765,2000 .

[62] L. R. Bachega, J. P. Bouillet, M. de Cássia Piccolo, L. Saint-André, J. M. Bouvet, Y. Nouvellon, J. L. de Moraes Gonçalves, A. Robin, J. P. Laclau. Decomposition of
Eucalyptus grandis and Acacia mangium leaves and fine roots in tropical conditions did not meet the Home Field Advantage hypothesis, Forest Ecology and Management, Vol.359, 33-43, 2016.

[63] Z. Zheng, M. Mamuti, H. Liu, Y. Shu, S. Hu, X. Wang, B. Li, L. Lin, X. Li. Effects of nutrient additions on litter decomposition regulated by phosphorus-induced changes in litter chemistry in a subtropical forest, China, Forest Ecology and Management, Vol.400, 123-128, 2017.

[64] M. D. Jewell, B. Shipley, A. Paquette, C. Messier, P. B. Reich. A traits-based test of the home-field advantage in mixed-species tree litter decomposition, Annals of Botany, Vol.116, No.5, 781-788, 2015.

[65] J. C. Neff, R. L. Reynolds, J. Belnap, P. Lamothe. Multi-decadal impacts of grazing on soil physical and biogeochemical properties in southeast Utah, Ecological Applications, Vol.15, No.1, 87-95, 2005.

[66] J. M. Christian, S. D. Wilson. Long-term ecosystem impacts of an introduced grass in the Northern Great Plains, Ecology, Vol.80, No.7, 2397-2407, 1999.

[67] W. L. Silver, R. K. Miya. Global patterns in root decomposition: Comparisons of climate and litter quality effects, Oecologia, Vol.129, No.3, 407-419, 2001.

[68] IPCC. Climate Change 2013: The Physical Science Basis. Contribution of Working Group I to the Fifth Assessment Report of the Intergovernmental Panel on Climate Change. Cambridge University Press, Cambridge, United Kingdom and New York, USA, 2013.

[69] V. Suseela, N. Tharayil. Decoupling the direct and indirect effects of climate on plant litter decomposition: Accounting for stress-induced modifications in plant chemistry, Global Change Biology, Vol.24, No.4, 1428-1451, 2018.

[70] M.-M. Coûteaux, C. Kurz, P. Bottner, A. Raschi. Influence of increased atmospheric $\mathrm{CO}_{2}$ concentration on quality of plant material and litter decomposition, Tree Physiology, Vol.19, No.4-5, 301-311, 1999.

[71] G. Hirschel, C. Körner, J. A. Arnone. Will rising atmospheric $\mathrm{CO} 2$ affect leaf litter quality and in situ decomposition rates in native plant communities? Oecologia, Vol.110, No.3, 387-392, 1997.

[72] R. J. Norby, M. F. Cotrufo, P. Ineson, E. G. O’Neill, J. G. Canadell. Elevated $\mathrm{CO}_{2}$, litter chemistry, and decomposition: A synthesis, Oecologia, Vol.127, No.2, 153-165, 2001.

[73] A. Koyama, J. M. Steinweg, M. L. Haddix, J. S. Dukes, M. D. Wallenstein. Soil bacterial community responses to altered precipitation and temperature regimes in an old field grassland are mediated by plants, FEMS Microbiology Ecology, Vol.94, No.1, 2018. 